INTERNATIONAL DESIGN CONFERENCE - DESIGN 2018

https://doi.org/10.21278/idc.2018.0485

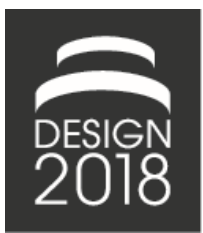

\title{
SIMULATING MULTISENSORY WINE TASTING EXPERIENCE
}

\author{
M. Carulli, M. Bordegoni, F. Ferrise, A. Gallace, M. Gustafsson and T. Pfuhl
}

\begin{abstract}
In this paper, we present the development of an application that allows us to simulate the multisensory experience of tasting a glass of wine. To this end, technologies for the sense of touch, sight, hearing, and smell have been integrated, creating an interactive multi-sensory experience. The user, after picking up a glass, activates an application in which he is guided by a virtual sommelier to make a tasting, and he is able to perceive the multi-sensory experience of the wine tasting experience. The paper describes the application and its potential use in marketing.
\end{abstract}

Keywords: user experience, virtual reality (VR), multisensory product experience

\section{Introduction}

One of the applications fields in which Virtual, Mixed or Augmented Reality (VR, MR or AR respectively) technologies, and interactive simulations in general, might have success is certainly that of product marketing. Typically, a product is conceived so as to capture the attention of potential customers and elicit an emotional reaction by appealing to their senses.

The low-cost VR, MR and AR technologies, which are today available on the market, make it easy for designers, with the help of marketing experts, psychologists and neuroscientists, to design product multisensory experiences, to quickly test the reaction of the potential customers and finally refine the results (Spence and Gallace, 2011; Ferrise et al., 2017). Although many of VR, MR and AR applications rely primarily on visual technologies, there are technologies for other senses such as hearing, touch, and olfaction. We do believe that, by properly integrating all these technologies, it is possible to create simple applications with a considerable potential for product marketing.

In this research activity, we decided to simulate an interactive wine tasting experience with three purposes: 1) to provide companies with a tool to support for the remote sale of wines; 2) to improve advertisement; 3 ) as a support tool for teaching people to become wine experts. Moreover, the system could be used in other applications, such as the design and the evaluation of the glass shapes, which is strictly related to the wine tasting and perception (Venturi et al., 2013).

It was decided to integrate VR, MR or AR technologies, of three different sensory modalities, i.e. sight, touch, and smell, in an unconventional way, that is, not with the aim of creating a completely immersive simulation environment, but in order to create a very simple but effective interactive experience. To this aim, low-cost small technologies have been integrated into real objects, i.e. a real glass, in order to augment the experience it can deliver to the various human senses. In particular, in the application described in the paper, some sensors detect the action that a user performs on a real wine glass and communicate it to an application that activates an interactive movie. Through this video, the user receives instructions on how to taste the wine according to the typical instructions provided by sommeliers and, while he/she does the suggested action, he/she receives tactile and olfactory 
information related to the type of wine that the glass should contain. In this way, the user is able to experience a number of different simulated wines.

In the paper, we describe the theoretical foundations of this research as well as the interactive application developed.

\section{Related works}

The importance of eliciting the senses of touch and olfaction in product experience design

The importance of eliciting all the human senses when designing the product experience is very wellknown in the marketing world. For example, concerning the sense of touch, in the last few years tactile sensations are used more often than ever before within advertising techniques to create stronger emotional and cognitive connections between the product or the brand and the consumer. Tactile sensations, are now becoming important to the field of packaging innovation, where visual properties of containers has already been exploited to a maximum level and new solutions are needed (Gallace and Spence, 2014; Gallace, 2015; Spence, 2016). This interest is also due to the fact that the sense of touch is often defined 'the most arousing' of the human senses (Field, 2014) and that neuroscientific evidence has proven the effectiveness of this modality in activating the orbitofrontal cortex, a deep brain structure involved in the perception of pleasure (e.g., Rolls et al., 2003; see also Löken et al., 2009, for the neural fibres involved in the more pleasant aspects of touch). It is worth noting here that the activation of this part of the brain has been shown to be correlated to the willingness of consumers to pay a higher price to get a product (e.g., Plassmann et al., 2007; see also Knutson et al., 2007). Similarly, a recent study showed that the psychophysiological reactions elicited by materials rubbed on our skin are much larger than those elicited by sight alone (Etzi and Gallace, 2016). That is, the contact with object, more than their sight, elicits physiological reactions linked to our behaviour and emotions. As far as this point is concerned a neurophysiological model of choice behaviour, suggests that under condition of overload (but not only), physiological reactions and their link with memory traces of previous product experiences often drive our final decisions (e.g., Damasio et al., 1991).

Another very important, and relatively underexploited, sense for marketing purposes is olfaction. Olfaction has a great importance in our daily life, because it is devoted to acquire and interpret chemical signals in the environment and supports some basic biological and behavioural functions, as dangers recognition, identification of food, and social communication (Nakamoto, 2013).

Moreover, due to the fact that many regions of the human brain are involved in the process of olfaction, olfactory stimulus can evoke memories and unconscious responses at the emotional level even before it is consciously perceived and recognized. For these reasons, odours can improve a person's mood, as well as enhance learning activities, increase attention level, and are deeply evocative (Porcherot et al., 2010).

Importantly, olfaction has been shown to affect our evaluation of visual stimuli. For example, Demattè and her colleagues showed that female participants rate male faces as less attractive when presented together with an unpleasant odour, as compared to a condition where the faces are presented together with a pleasant odour or odourless medical air (Demattè et al., 2007).

A recent study showed that similar effects, related to the modulation of people preference due to olfactory presentation, can be found also for commercial products. For this very reason, smells are more often than ever before used in marketing campaigns (e.g., Rimkute et al., 2016).

Moreover, in the marketing research area many studies have been done on the use of smells and their properties. For example, odours can influence moods: while pleasant odours can induce positive moods, unpleasant odours can induce negative ones (Rétiveau et al., 2004). This property has been applied for eliciting positive moods in people. Some studies found out that congruent odours in the environment can be used for improving the time spent by customers in a store (Mitchell et al., 1995). Moreover, the use of pleasant scents in the environment can enhance evaluations of products (Bosmans, 2006) and of stores (Spangenberg and Crowley, 1996) in comparison with evaluations in no scent conditions.

Also, odours can be used for communicating information about products as, for instance, perfumes, household cleaners and food. In the mass market, the perceived quality of the products is often 
associated with their odours (Gatti et al., 2014). Consequently, companies add odours to several commercial products, such as household cleaners, body washes and soaps, fabric softeners and so on.

Having acknowledged the relevance of touch and olfaction, it is important to observe that in many shopping situations, just as in our everyday interactions with the environment, information from a product does not come from a single sensory modality, but from a number of different sensorial stimuli. That is, multisensory integration is necessary to shape our product experience and to determine our choices. The importance of engaging several of a customer's senses, and of doing so in a multisensorially-congruent manner to develop product appreciation, loyalty and engagement, is, though, increasingly being recognized (see de Chernatony and McDonald, 1992; Neff, 2000; Spence, 2002; Lindstrom, 2005; Springer, 2008).

In the area of foods, natural and artificial flavours are usually used to supplement food organoleptic characteristics. In these cases, the use of these additive aromas allows companies to standardize the taste, filling any gaps caused by the food characteristics, and the possible changes in food preparation.

A large area of research concerns the perception of food and beverage. Regarding wine tasting, among the others, research works about the perception of beverages have been carried out (Desmet and Schifferstein, 2008; Schifferstein, 2009; Schifferstein, 2010; Schifferstein et al., 2013; Schifferstein, 2015). For instance, Morrot et al. (2001) presented a psychophysical experiment in which a white wine, artificially coloured with odourless red dye, was olfactory described as a red wine by a panel of tasters. Their results suggest that, because of the visual information, the tasters discounted the olfactory information.

In the area of VR and AR, in the last few years many research projects concerning the use of these technologies for simulating and improving the food experience have been carried out.

\section{Virtual, Mixed and Augmented Reality}

Concerning the possibility to influence the tasting experience by using a multisensory augmented experience, Narumi et al. (2011) developed a "pseudo-gustatory" display for creating a gustatory sensation. This display presents flavours by means of a cross-modal effect elicited by visual and olfactory AR. For this purpose, they developed the "MetaCookie", by using the Edible Marker system, which can detect the state of each piece of bitten or divided food in real time, and the "pseudo-gustation" method to change the perceived taste of food by changing its appearance and scent. Also some companies have developed VR applications related to food and beverage experiences. For instance, the Fourth Reality company developed a virtual reality experience in which a virtual vineyard is presented to the user, and information about different wines is added. Through this experience the user gets the impression of participating in a real wine tasting in a genuine environment (https://www.fourthreality.com/virtualrealitywinetasting). After the introduction of the wine the user takes off the head mounted display and tastes the wine presented.

However, no research works in which visual, haptic and olfactory stimuli are integrated are known to the authors.

In the area of VR and simulation, several studies have focused on presenting odours in virtual environments, by developing devices named olfactory displays. An olfactory display is a computercontrolled device that generates scented air and provides a user with odours.

In order to develop an olfactory display, it is necessary to take into account two main characteristics of the olfaction, since it is a chemical sense. The first one concerns the non-linearity of the olfaction (a change of intensity of the stimulus can result in a qualitative change in the subjective sensation), while the second one is that there is not consensus on a classification of "primary" smells, and researchers are still trying to find out the minimum number of smell components required for achieving an acceptable quality of expressing arbitrary smells. Then, researchers in the ICT area have reduced the number of smell components to use according to specific applications in which they would like to use their devices. Specifically, because humans sense odours through the air, the role of an olfactory display is to make scented air from odour materials in a stocked form (liquid, soaked in porous materials, encapsulated or gelled) with the desired components and concentration, and to deliver the scented air to the human olfactory organ. There are various technologies used to develop an olfactory display, categorized by scent generation methods and scent delivery methods (see Nakamoto, 2013). For what concerns scent 
generation methods there are, for example, natural vaporization, airflow-based vaporization, heating, airflow-based atomization, direct atomization - piezoelectric method, and ultrasonic atomization. For what concerns scent delivery methods, there is, for example, the natural diffusion/convection, using wind, vortex ring, using tubes, and by using direct injection. These technologies have been used in several research projects that focused on the development of olfactory display for specific purpose.

For instance, Yanagida et al. (2003) proposed an unencumbering olfactory display that conveys a clump of scented air from a remote place to the user's nose by using an air cannon that generates toroidal vortices of the scented air. Kim et al. (2009) focused their research on developing an olfactory display based on a chemical container of temperature responsive hydrogel, which can have reversible phase transition between sol and gel, and controlled release of aroma by using a Peltier module to control the temperature. Yamada et al. (2006) developed and evaluated two prototypes of wearable olfactory displays (the first prototype deals with odour in the gaseous state, while the second one uses odour in the liquid state) to present the spatiality of odour in an outdoor environment. Viswadhara Meenakshi and Sowmya (2003) developed an olfactory device named ESTER (Experiencing Smell Through Electronic Reality), whose main purpose is to make people experience the sense of smell through an electronic media. ESTER is made of a hardware circuitry to store 4 or 8 scents. Also, Yoshimura and Sakashita (2006) developed an olfactory device for emitting a real perfume into the user's immediate area, when a mail with a key program is read via Internet. Matsukura et al. (2012) proposed an olfactory display that presents a virtual odour at an arbitrary position on a two-dimensional screen. Hirota et al. (2013) developed an approach to implement and evaluate smell display to be used in multi-sensory theatres. They developed both an olfactory display system and a sensor system. In the olfactory display system, smells are vaporized in chambers to achieve saturated state, and then plain air is infusing for pushed out the scented air.

Finally, some companies have developed and tried to sell virtual olfactory displays for personal computer use (Davide et al., 2001). Some examples are AromaJet, DigiScents-iSmell, ScentAir (www.scentair.com), Aromajoin (aromajoin.com) and TriSenx. They use a number of odours stored in cartridge and, upon receiving a signal describing an odour, they release a mixture of these odours. This is done, for example, by using pumps, and the resulting scented air is blown towards the user with a small fan.

Due to the fact that personal olfactory displays developed so far try to simulate a great number of odours, these are often very limited (in the number of scents that can be stored and generated, in the quantity of scents that can be emitted, in the distance that the scented air can cover, and so on), cumbersome and they have not found commercial success.

So, some of the authors have developed some prototypes of Olfactory Display and have evaluated their performances in several applications for products evaluation (Bordegoni and Carulli, 2016), for improving the drivers' attention level (Bordegoni et al., 2016), for heritage studies (Terracciano et al., 2017) and for improving the reading experience (Bordegoni et al., 2017).

\section{Multisensory wine tasting experience}

The hypothesis at the basis of this work is related to the use tactile and olfactory technologies, combined with visual and sound technologies, to simulate wine tasting experiences. The concept consists of a guided wine tasting where the user is led through the experience by a professional sommelier.

The aim of the application is to lead non-expert users in wine tasting, to be used as an advertisement tool, or to provide support for the remote sale of wines. Users can experience visual, tactile and olfactory characteristics of wines even in their absence. This application could be particularly effective in the case of wines difficult to find or very expensive to buy, and also to practice in recognising wines through their visual and olfactory characteristics.

In order to achieve this result, the wine tasting experience and the role of the sensory modalities through which users typically enjoy this experience have been analysed.

The common actions during a wine tasting are to see, swirl, smell, sip and spit the wine. Specifically, firstly the wine is poured into the glass. So, the user lifts the glass and, depending on the type of wine, turns the glass to release the aromas present in the wine, and to analyse its colour. The best method to release the aromas of the wines is by tilting the wine glass with a 30 degrees angle and rotating it counter 
clockwise. Then, the user brings the glass to the nose to smell the aromas of the wine. When smelling, it is important that the user holds the wine glass directly under its nose and takes a deep breath in (Wine Styles, 2017). Finally, the user tastes the wine.

In this process, all these actions correspond to many sensorial cues that contribute to the multisensory experience of wine tasting, which culminates in the wine taste.

With the aim of creating a multisensory system for the wine tasting simulation, authors defined an architecture in which devices for creating visual, tactile and olfactory stimuli into a univocal flow are integrated.

Firstly, the system is based on an interactive movie through which the user is guided into a tour. Indeed, through some videos, the user is asked to make some choices (such as the type of wine to taste), is provided with information about the wine, and its visual and olfactory characteristics and is asked to carry out some actions.

Synchronised with the videos, several sensors and actuators are integrated into the system in order to simulate the multi-sensory experience, through tactile and olfactory stimuli. These sensors and actuators are connected and physically integrated in appropriate positions into a glass, which has been chosen as the interaction interface between the user and the system. All these components of the system and their integration are described in Section 3.2. In the first video, a short introduction to the virtual wine tasting is given to the user, and he/she is asked to choose the typology of wine to virtually taste (red or a white wine).

This step allows to define the following phases of the experience based on the characteristics of the wine: choosing a white wine the characteristics that the user will experience will be consistent with this type of wine, and so will also be in the choice of a red wine.

Consequently, a video specifically designed and developed for the wine typology starts. In this second video a sommelier explains the main characteristic of the wine and, at the end, asks the user to pick up the glass.

At this point, the interaction between the user and the system is guided by a proximity sensor that allows detecting the distance between the glass and the table and, therefore, if the glass is lifted or not.

When the user picks up the glass and the distance change, a third video starts.

During the third video, the user is asked to rotate the glass in order to analyse the colour of the wine and to release its aromas. Through an actuator integrated into the system the user is able to perceive some tactile cues related to the movement of the wine inside the glass. Then, one of the two olfactory devices (one for the red wine and the other for the white) produces the aromas, which are eventually smelled by the user. So, the user is able to see, swirl and smell the wine.

The complete setup is shown in Figure 1. A detail of the glass, with sensors and actuators is shown in Figure 2 .

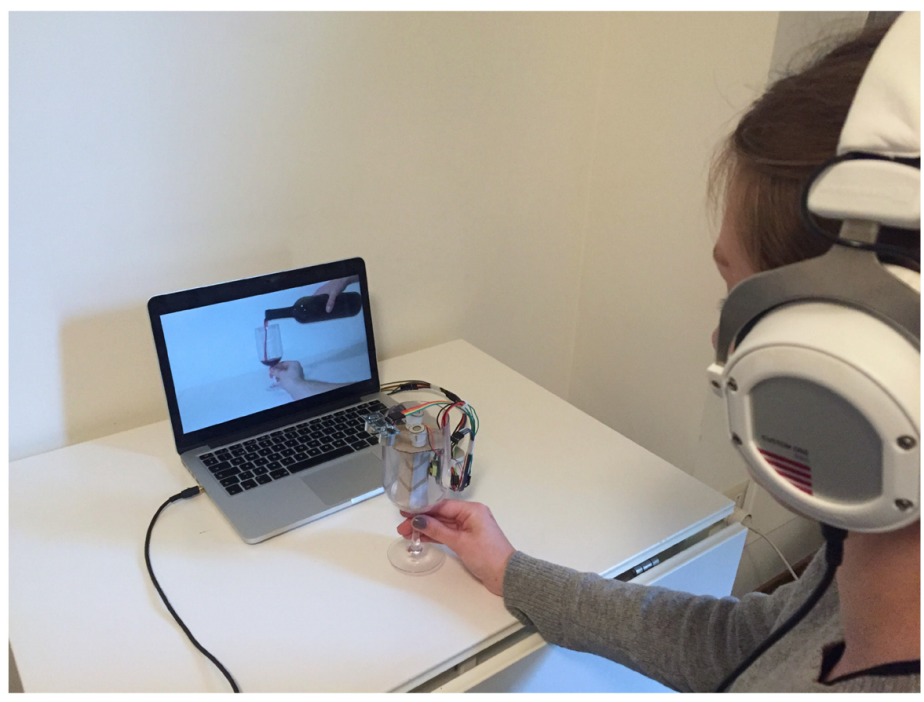

Figure 1. The setup for the wine tasting experience 

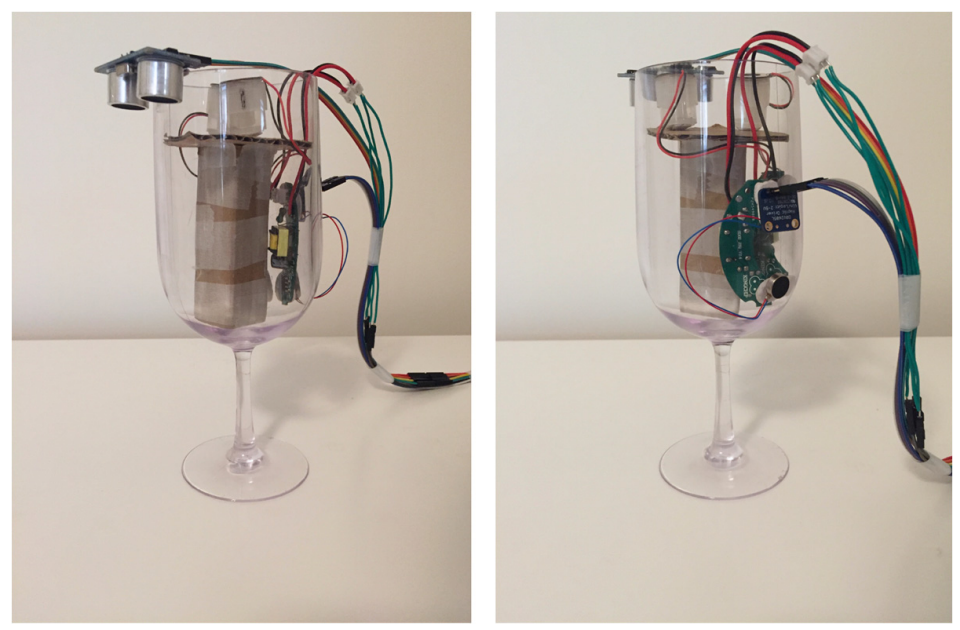

Figure 2. The prototype of the glass containing sensors and actuators

\subsection{Choice of the video and audio contents}

In order to obtain a realistic and engaging experience, the contents of the videos should correspond to an actual wine tasting. Therefore, the videos have been developed with the aim of representing the actual wine tasting experience. Moreover, these are based on the idea of leading step-by-step the user in the wine tasting process by using the phenomenon of virtuous imitation. So, the actions in the video are carried out by a "virtual agent", and the user should follow the audio instructions and mimic the actions as in a "mirror".

In the first video no objects are placed in front of the user: the sommelier, who is out of the camera view, asks which wine typology the user likes best (red or white).

After the selection of the wine typology, the second video starts with the view of an empty glass, in which the sommelier pours the wine and explains its characteristics. So, the user is asked to pick up the glass and the hand of a "virtual agent" picking up the wine glass is shown.

When the glass is lifted, the last video starts. In this video, the user has a look at the wine, both from a distance and close. Then, the "virtual agent" swirls the wine glass and finally puts the wine glass down, and the user is asked to carry out the same actions.

In the videos the only objects are the glass, the wine bottle, the table and the background. Both the table and the background are white to distinguish the wine and the wine glass. This makes it easy for the user to know what to focus on and not to be distracted by the environment.

For the videos regular wine bottles are used. Labels on the wine bottles have been removed to avoid distractions and misunderstandings. The glass used in the videos is the same of that used in the real environment. By using this approach the user can see and handle one glass during the experience.

The wine presented is red or white to clarify to the user that he or she smells either a red wine or a white wine. Even though the aroma might not seem convincing enough, the colour of the wine might trick the user (Morrot et al., 2001).

The videos have been recorded with a camera fixed to a table with a tripod in order to generate a still picture. The camera has been placed at a distance from the table corresponding to the eye-level to stage the perspective of the user.

The sounds that have been recorded in the videos are those connected to the experience, such as the wine pouring. Other sounds, such as the background sound, have been eliminated to avoid distractions. The voice of the sommelier has been recorded and added to the videos to inform the user about the wines and to explain the actions to perform during the tasting.

\subsection{System architecture and tactile and olfactory cues delivery}

Several sensors and actuators are integrated into the system and are synchronised with the videos, in order to simulate the multi-sensory experience, through tactile and olfactory stimuli. As previously 
introduced, these sensors and actuators are integrated into a glass, which represents the interaction interface between the user and the system.

Specifically, a proximity sensor has been integrated to measure the distance between the glass position and the table; a Linear Resonant Actuator (LRA) and a Micro Controller (TIDRV2605L) have been integrated for the tactile simulation; and two olfactory devices for the delivery of the wine aromas.

All these sensors and actuators are controlled by an Arduino UNO Rev 3 board, which is connected to a computer.

A representation of the system architecture is shown in Figure 3.

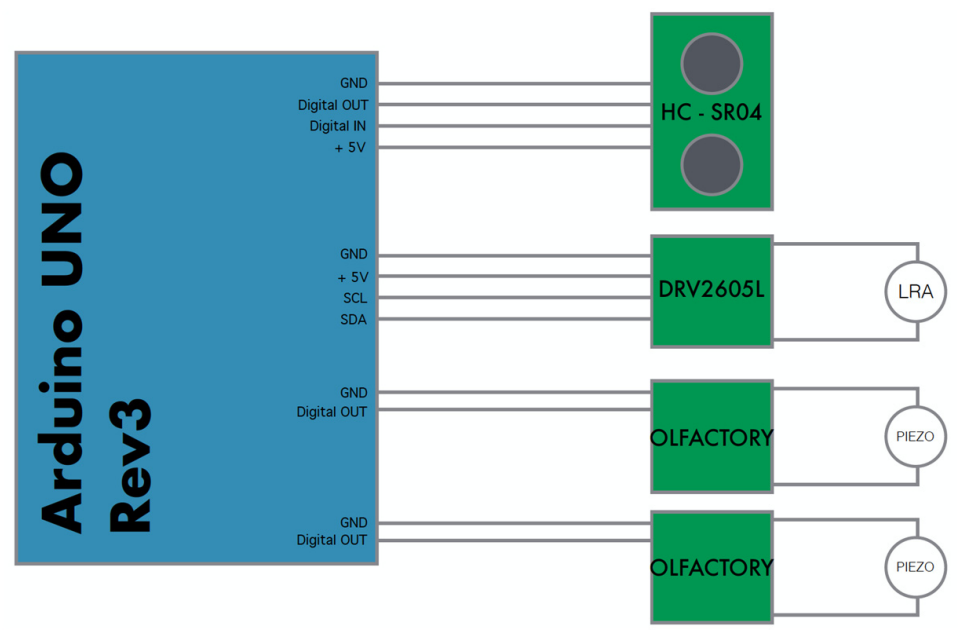

Figure 3. Graphical representation of the system architecture

The Linear Resonant Actuator (LRA) and the Micro Controller (TIDRV2605L) are used for simulating the tactile feedback. Specifically, a very simplified tactile feedback is given to the user twice during the wine tasting. The inspiration for the design of the tactile cues and their integration with a real video comes from the demo described by Actronika (http://www.actronika.com/news-2/). The first haptic interaction takes place when the sommelier starts pouring the wine and the second when the user is swirling the wine. In a first approach some vibration patterns are created using the on-board library of effects on the micro controller, DRV2605L, chip. The specific patterns are chosen to match the vibrations that the user feels when actual wine is poured and swirled.

Concerning the olfactory simulation, the olfactory displays have been developed by using piezoelectric actuators to create a "scented fog" and disperse it into the air. Specifically, it has been decided to use the ultrasonic atomization method (in which fine particles from a liquid are generated by using ultrasonic energy) for the generation and the delivery of the aromas.

By using this technology, it is possible to obtain a lightweight and very small device, which can be placed into the glass, and to control the odour intensity and the frequency of emission, which cannot be controlled with other technologies (for example, with natural vaporization).

The device consists of air cannons for the generation and the delivery of the odour. In each air cannon it is placed a small cylinder of porous cotton and used as scented water cartridge. The cylinder of cotton is drenched with scented water and it is connected to the piezoelectric actuator. So, when the piezoelectric actuator is activated, under the effect of ultrasonic energy, a scented mist is generated and released in the air, which is eventually smelled by the user.

In this application, two commercial water-soluble aromas, one for the red wine and the other for white wine, are used to provide the user with a sample wine taste. These aromas have been diluted with water and then used for drenching the water cartridge. The aromas are shown in Figure 4.

The olfactory displays have been mounted inside the glass. The authors have chosen this solution to spray the scented air near the user's nose. Moreover, the user can smell the aromas from the glass of wine, similarly to an actual wine tasting experience. The setup is shown in Figure 4. 

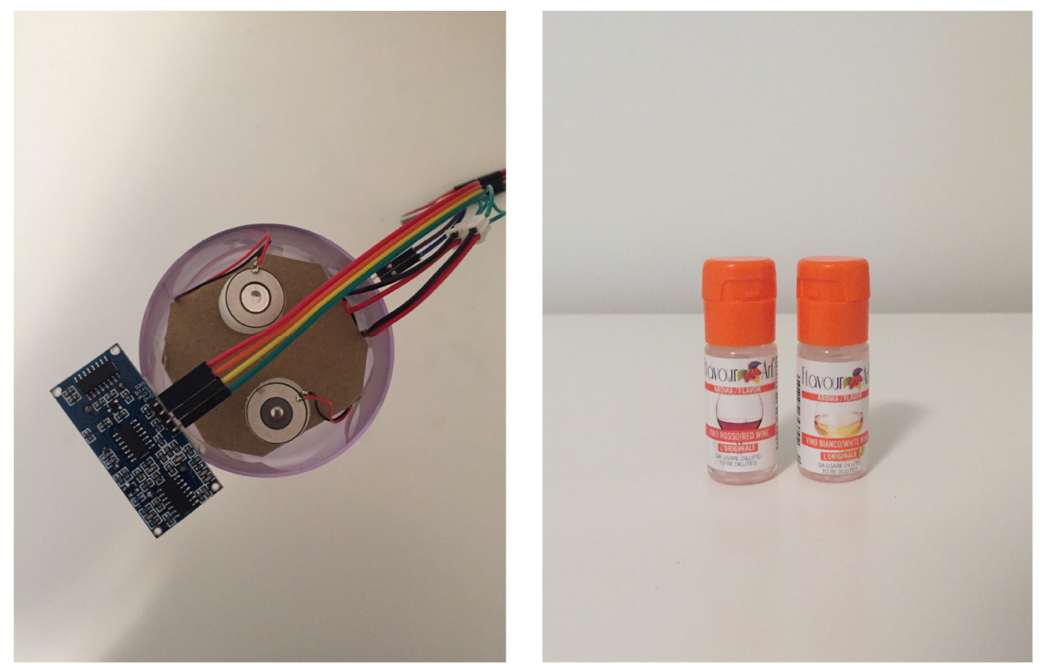

Figure 4. The olfactory displays and the aromas

\section{Conclusions}

The correct combination of low-cost technologies for different senses can lead to the creation of very simple interactive experiences with a very relevant potential for marketing purposes. In this paper, we described an application in which vision, hearing, tactile and olfactory technologies have been combined to create an interactive multisensory wine tasting experience. The result is a proof of concept that can be improved on different aspects in order to represent an even more realistic experience. The tactile component, for example, has a rather simplified rendering, compared to the complexity of tactile information coming from the simple handling of a full glass of a liquid. As for the olfactory part, the application can be improved by introducing additional types of odours. The cables going from the glass to the microcontroller could affect the handling and tilting thus reducing the performances of the system. So, the possibility to integrate a Bluetooth module and a battery can improve the experience. Finally, for the visual part, we can also use an head-mounted display to increase the level of immersion. The use of such an immersive display, however, would introduce the problem of tracking the movement of the hands and represent them, through an avatar, within the virtual environment, and also to guarantee the perfect correspondence between the virtual and the real glass.

Despite these limitations, even the current application has a considerable potential and in the future will be tested with users. Moreover, this device could be used in other applications related with the wines perception.

\section{References}

Bordegoni, M. and Carulli, M. (2016), "Evaluating Industrial Products in an Innovative Visual-Olfactory Environment", Journal of Computing and Information Science in Engineering, Vol. 16 No. 3, pp. 030904 https://doi.org/10.1115/1.4033229

Bordegoni, M., Carulli, M. and Shi, Y. (2016), "Investigating the use of smell in vehicle-driver interaction", Proceedings of the ASME Design Engineering Technical Conference. https://doi.org/10.1115/DETC201660541

Bordegoni, M., Carulli, M., Shi, Y. and Ruscio, D. (2017), "Investigating the effects of odour integration in reading and learning experiences", Interaction Design and Architecture(s) Journal, Vol. 32, pp. 104-125.

Bosmans, A. (2006), "Scents and sensibility: When do (in)congruent ambient scents influence product evaluations?", Journal of Marketing, Vol. 70 No. 3, pp. 32-43. https://doi.org/10.1509/jmkg.70.3.32

Damasio, A.R., Tranel, D. and Damasio, H.C. (1991), "Somatic markers and the guidance of behavior: Theory and preliminary testing”, In: Levin, H.S., Eisenberg, H.M. and Benton, A.L. (Eds.), Frontal lobe function and dysfunction, Oxford University Press, New York, NY, US, pp. 217-229.

Davide, F., Holmberg, M. and Lundström, I. (2001), "Virtual olfactory interfaces: electronic noses and olfactory displays", Communications Through Virtual Technology: Identity Community and Technology in the Internet Age, IOS Press, Amsterdam. https://doi.org/10.1.1.3.5926 
De Chernatony, L. and McDonald, M. (1992), Creating powerful brands: the strategic route to success in consumer, industrial, and service markets, Butterworth-Heinemann.

Demattè, M.L., Österbauer, R. and Spence, C. (2007), "Olfactory cues modulate facial attractiveness", Chemical Senses, Vol. 32 No. 6, pp. 603-610. https://doi.org/10.1093/chemse/bjm030

Desmet, P.M.A. and Schifferstein, H.N.J. (2008), "Positive and negative emotions associated with food experience", Appetite, Vol. 50, pp. 290-301. https://doi.org/10.1016/j.appet.2007.08.003

Etzi, R. and Gallace, A. (2016), "The arousing power of everyday materials: an analysis of the physiological and behavioral responses to visually and tactually presented textures", Experimental brain research, Vol. 234 No. 6, pp. 1659-1666. https://doi.org/10.1007/s00221-016-4574-z

Ferrise, F., Graziosi, S. and Bordegoni, M. (2017), "Prototyping strategies for multisensory product experience engineering", Journal of Intelligent Manufacturing, Vol. 28 No. 7, pp. 1695-1707. https://doi.org/10.1007/s10845-015-1163-0

Field, T. (2014), Touch, MIT Press.

Gallace, A. (2015), "Tactile Processing”, In: Wright, J.D. (Ed.), International Encyclopedia of the Social \& Behavioral Sciences, 2nd ed., Vol. 24, Elsevier, Oxford, pp. 14-19. https://doi.org/10.1016/B978-0-08097086-8.23176-0

Gallace, A. and Spence, C. (2014), In touch with the future: The sense of touch from cognitive neuroscience to virtual reality, OUP Oxford. https://doi.org/10.1093/acprof:oso/9780199644469.001.0001

Gatti, E., Bordegoni, M. and Spence, C. (2014), "Investigating the influence of colour, weight, and fragrance intensity on the perception of liquid bath soap: An experimental study", Food Quality and Preference, Vol. 31, pp. 56-64. https://doi.org/10.1016/j.foodqual.2013.08.004

Hirota, K., Ito, Y., Amemiya, T. and Ikei, Y. (2013), "Presentation of Odor in Multi-Sensory Theater", In: Shumaker, R. (Ed.), Virtual, Augmented and Mixed Reality. Systems and Applications, Springer, Berlin, Heidelberg, pp. 372-379. https://doi.org/10.1007/978-3-642-39420-1_39

Kim, D.W., Nishimoto, K., Kunifuji, S., Cho, Y.H., Kawakami, Y. and Ando, H. (2009), "Development of AromaCard Based Soundless Olfactory Display, Electronics, Circuits, and Systems", 6th IEEE International Conference on Electronics, Circuits, and Systems, ICECS 2009, Yasmine Hammamet, Tunesia, December 1319, 2009.

Knutson, B., Rick, S., Wimmer, G.E., Prelec, D. and Loewenstein, G. (2007), "Neural predictors of purchases", Neuron, Vol. 53 No. 1, pp. 147-156. https://doi.org/10.1016/j.neuron.2006.11.010

Lindstrom, M. (2005), "Broad sensory branding”, Journal of Product \& Brand Management, Vol. 14 No. 2, pp. 84-87. https://doi.org/10.1108/10610420510592554

Löken, L.S., Wessberg, J., McGlone, F. and Olausson, H. (2009), "Coding of pleasant touch by unmyelinated afferents in humans”, Nature neuroscience, Vol. 12 No. 5, pp. 547-548. https://doi.org/10.1038/nn.2312

Matsukura, H., Yoneda, T. and Ishida, H. (2012), "Smelling Screen: Technique to Present a Virtual Odor Source at an Arbitrary Position on a Screen", IEEE Virtual Reality 2012. https://doi.org/10.1109/VR.2012.6180915

Mitchell, D.J., Kahn, B.E. and Knasko, S.C. (1995), "There's something in the air: Effects of congruent or incongruent ambient odor on consumer decision making”, The Journal of Consumer Research, Vol. 22 No. 2 , pp. 229-238. https://doi.org/10.1086/209447

Morrot, G., Brochet, F. and Dubourdieu, D. (2001), "The color of odors”, Brain and Language, Vol. 79 No. 2 , pp. 309-320. https://doi.org/10.1006/brln.2001.2493

Nakamoto, T. (2013), Human Olfactory Displays and Interfaces: Odor Sensing and Presentation, Information Science reference.

Narumi, T., Nishizaka, S., Kajinami, T., Tanikawa, T. and Hirose, M. (2011), "Meta cookie: An illusion-based gustatory display", International Conference on Virtual and Mixed Reality, pp. 260-269. https://doi.org/10.1007/978-3-642-22021-0_29

Neff, J. (2000), Product scents hide absence of true innovation. [online] Advertising Age. Available at: http://adage.com/article/news/product-scents-hide-absence-true-innovation/59353

Plassmann, H., O'Doherty, J. and Rangel, A. (2007), "Orbitofrontal cortex encodes willingness to pay in everyday economic transactions", Journal of neuroscience, Vol. 27 No. 37, pp. 9984-9988. https://doi.org/10.1523/JNEUROSCI.2131-07.2007

Porcherot, C., Delplanque, S., Raviot-Derrien, S., Le Calvé, B., Chrea, C. and Gaudreau N. (2010), "How do you feel when you smell this? Optimization of a verbal measurement of odor-elicited emotions", Food Quality and Preference, Vol. 21, pp. 938-947.

Rétiveau, A.N., Chambers, I.V.E. and Milliken, G.A. (2004), "Common and specific effects of fine fragrances on the mood of women”, Journal of Sensory Studies, Vol. 19, pp. 373-394. https://doi.org/10.1111/j.1745459x.2004.102803.x

Rimkute, J., Moraes, C. and Ferreira, C. (2016), "The effects of scent on consumer behaviour", International Journal of Consumer Studies, Vol. 40, pp. 24-34. https://doi.org/10.1111/ijcs.12206 
Rolls, E.T., O’Doherty, J., Kringelbach, M.L., Francis, S., Bowtell, R. and McGlone, F. (2003), "Representations of pleasant and painful touch in the human orbitofrontal and cingulate cortices", Cerebral cortex, Vol. 13 No. 3, pp. 308-317. https://doi.org/10.1093/cercor/13.3.308

Schifferstein, H.N.J. (2015), "Employing consumer research for creating new and engaging food experiences in a changing world", Current Opinion in Food Science, Vol. 3, pp. 27-32. https://doi.org/10.1016/j.cofs.2014.11.004

Schifferstein, H.N.J., Fenko, A., Desmet, P.M.A., Labbe, D. and Martin, N. (2013), "Influence of package design on the dynamics of multisensory and emotional food experience", Food Quality and Preference, Vol. 27 No. 1, pp. 18-25. https://doi.org/10.1016/j.foodqual.2012.06.003

Schifferstein, H.N.J. (2010), "From salad to bowl: the role of sensory analysis in product experience research", Food Quality and Preference, Vol. 21 No. 8, pp. 1059-1067. https://doi.org/10.1016/j.foodqual.2010.07.007

Schifferstein, H.N.J. (2009), “The drinking experience: cup or content?”, Food Quality and Preference, Vol. 20 No. 3, pp. 268-276. https://doi.org/10.1016/j.foodqual.2008.11.003

Spangenberg, E.R. and Crowley, A.E. (1996), "Improving the store environment: Do olfactory cues affect evaluations and behaviors?", The Journal of Marketing, Vol. 60 No. 2, pp. 67-80. https://doi.org/10.2307/1251931

Spence, C. (2002), The ICI report on the secret of the senses, Communication Group London.

Spence, C. (2016), "Multisensory packaging design: Colour, shape, texture, sound, and smell”, In: Burgess, P. (Ed.), Integrating the packaging and product experience: A route to consumer satisfaction, Elsevier, pp. 1-22. https://doi.org/10.1016/B978-0-08-100356-5.00001-2

Spence, C. and Gallace, A. (2011), "Multisensory design: Reaching out to touch the consumer", Psychology \& Marketing, Vol. 28 No. 3, pp. 267-308. https://doi.org/10.1002/mar.20392

Springer, C. (2008), Multisensuale Markenfuehrung: Eine verhaltenswissenschaftliche Analyse unter besonderer Beruecksichtigung von Brands Lands in der Automobil-wirtschaft, Gabler Verlag, Wiesbaden.

Terracciano, A., Dima, M., Carulli, M. and Bordegoni, M. (2017), "Mapping Memory Routes: A multisensory interface for sensorial urbanism and critical heritage studies", Conference on Human Factors in Computing Systems.

Venturi, F., Zinnai, A., Fantoni, G., Gabelloni, D. and Razionale, A.V. (2013), "Glass and wine: the indissoluble marriage", 19th International Conference on Engineering Design (ICED 2013), Seoul, Korea.

Viswadhara Meenakshi, V. and Sowmya, K. (2003), "ESTER: Experiencing Smell Through Electronic Reality", 2003 IEEE International Conference on Consumer Electronics, 2003, ICCE.

Wine Styles (2017), How to Taste Wine. [online] Available at: http://www.winestyles.com/how-to-taste-wine (accessed 08.02.2017).

Yamada, T., Yokoyama, S., Tanikawa, T., Hirota, K. and Hirose, M. (2006), "Wearable Olfactory Display: Using Odor in Outdoor Environment”, IEEE Virtual Reality Conference, 2006. https://doi.org/10.1109/VR.2006.147

Yanagida, Y., Noma, H., Tetsutani, N. and Tomono, A. (2003), “An Unencumbering, Localized Olfactory Display", CHI '03 Extended Abstracts on Human Factors in Computing Systems, Ft. Lauderdale, Florida, USA, April 5-10, 2003, pp. 988-989.

Yoshimura, T. and Sakashita, Y. (2006), "Development of a Perfume Emission System via Internet”, Journal of Computer Chemistry, Japan, Vol. 5 No. 4, pp. 227-230. https://doi.org/10.2477/jccj.5.227

Dr. Marina Carulli, Assistant Professor

Politecnico di Milano, Mechanical Engineering Department

Via La Masa 1, 20154 Milano, Italy

Email: marina.carulli@polimi.it 